Research Article

\title{
Study on Injection Molding Process Simulation and Process Parameter Optimization of Automobile Instrument Light Guiding Support
}

\author{
Hu Wu (D), Youmin Wang $(D$, and Mingyue Fang \\ School of Mechanical Engineering, Anhui Polytechnic University, Wuhu, Anhui 241000, China \\ Correspondence should be addressed to Youmin Wang; wymtlf@ahpu.edu.cn
}

Received 29 March 2021; Revised 28 April 2021; Accepted 12 May 2021; Published 24 May 2021

Academic Editor: Ashwini Kumar

Copyright ( $2021 \mathrm{Hu}$ Wu et al. This is an open access article distributed under the Creative Commons Attribution License, which permits unrestricted use, distribution, and reproduction in any medium, provided the original work is properly cited.

\begin{abstract}
In the present study, Moldflow ${ }^{\circledR}$ software is applied to simulate the injection molding of automobile instrument light guide bracket and optimize the injection gate position. In this regard, Taguchi orthogonal experimental design is adopted, and five processing parameters, the mold temperature, melt temperature, cooling time, packing pressure, and packing time, are considered as the test factors. Moreover, volume shrinkage and warping amount are considered as quality evaluation indices. Then range analysis and variance analysis are carried out to obtain the optimal combination of molding parameters with the volume shrinkage rate and the warpage amount. The grey correlation analysis was used to analyze the test results and obtain the optimal combination of volume shrinkage rate and amount of warping. Based on the performed simulations, it is found that the maximum volume shrinkage rate and the maximum amount of warping in the optimal design are $6.753 \%$ and $1.999 \mathrm{~mm}$, respectively. According to the optimal process parameters, the injection molding of the automobile instrument light guide bracket meets the quality requirements.
\end{abstract}

\section{Introduction}

With the rapid development of the plastic industry, plastic products are widely used in different automobile parts due to their unique properties such as lightweight, low price, high insulation, and reasonable corrosion resistance. Currently, plastic parts have a large share in reducing car weight and reducing manufacturing costs. However, inappropriate parameters in the injection molding process may result in numerous defects in the final plastic products. Therefore, it is of significant importance to simulate and analyze each link of the injection molding process before the production of plastic parts to obtain the optimized injection molding process parameters, control defects, ensure the product quality, and improve the production efficiency.

Moldflow ${ }^{\circledR}$ is the most widely applied commercial software in simulating plastic injection molding. Currently, Moldflow Insight can be applied to simulate the whole injection molding process, including the flow, packing pressure, warpage, shrinkage, cavitation, and fiber orientation [1]. Moreover, Moldflow can be applied to simulate the injection molding process of plastic parts and predict probable defects in plastic parts. Accordingly, the injection molding process parameters can be optimized, which can reduce the production cost and improve the production efficiency, and effectively avoid the defects such as bubbles, weld marks, shrinkage holes, and excessive warping deformation in plastic parts [2].

Studies show that many parameters affect the forming process, and each parameter is interrelated and mutually restricted. Moreover, the influence degree of each parameter on the product quality is different [3]. In this regard, scholars studied the influence of numerous molding parameters on the quality of plastic parts through orthogonal experimental design methods or the combination of an intelligent algorithm and CAE (Computer Aided Engineering) technology [4]. Wang [5] used an orthogonal experimental design method to analyze the influence of molding parameters on 
the warpage of the wall switch bracket. Within the allowable range, the process parameters were taken as 4 levels and 5 factors, and the optimal process parameters were found through the range analysis. Tang et al. [6] took volume shrinkage rate and amount of warping as quality evaluation indices and established a response surface model between molding parameters and quality evaluation indices to optimize affecting parameters. Jing et al. [7] optimized the process parameters by Moldflow and Taguchi orthogonal test methods and obtained the influence of process parameters on the warpage and shrinkage mark. Kumar et al. [8] studied the influence of process parameters on the injection molding of PMC cam bushing and optimized the process parameters to improve the cam bushing quality. The design was carried out according to the Taguchi orthogonal test, while the optimization was carried out through the grey correlation analysis and response data. Hentati et al. [9] used Taguchi orthogonal test to conduct injection molding experiments with 4 factors and 3 levels through the statistical design method. To this end, they employed the Moldflow software in the simulation and analysis and obtained the optimal process parameters accordingly. It was found that the optimal combination parameters provide better shear stress for injection molding of PC/ABS parts. Mukras et al. [10] determined the optimal molding process parameters to minimize the molding defects through experimental multiobjective optimization and then studied the warpage and volume shrinkage of the product quality.

In the present study, the automobile instrument light guide bracket is considered as the research object. In this regard, the mold gate and cooling systems are simulated by Moldflow software to obtain the optimal gate position. Then the range analysis and variance analysis are carried out to optimize the molding process parameters, volume shrinkage rate and amount of warping. Finally, the grey correlation analysis is applied to process the test results and obtain the optimal combination of the volume shrinkage rate and warping.

\section{Numerical Simulation of Injection Molding Process of the Automobile Instrument Light Guide Bracket}

Prior to the numerical simulation of injection molding, it is necessary to establish a 3D model of parts, determine optimal gate position, and simulate the gating system and the cooling system.

2.1. Establishment of the 3D Model for Light Guide Bracket of the Automobile Instrument. In this section, Creo is used to draw the 3D model of the light guide bracket of the automobile. Figure 1 shows that the part shape is complex, and there are many cavities and strong ribs at the bottom. The overall dimension of the part is $367 \mathrm{~mm} \times 169 \mathrm{~mm} \times 25 \mathrm{~mm}$, and a $2.5 \mathrm{~mm}$ thick wall is evenly distributed around the part. It should be indicated that the bracket should fit with the lower PCB board and the top plate, so it is necessary to provide a good flatness in the bracket. Consequently, the volume shrinkage rate and the warping of the part during the molding process should be minimized.

2.2. Finding the Optimal Gate Location. The optimal gate location area recommended by the optimal gate matching should be combined with the structural characteristics of the plastic part. Figure 2 reveals that the recommended optimal gate position is on the part surface. However, the shape of automobile instrument light guide bracket is complex, and there are many cavities and ribs at the bottom, so the gate position cannot be on the part surface. After synthesizing these points, four gate schemes are preliminarily considered. Figure 3 shows the gate positions of each scheme, where Figures 3(a)3 (d) correspond to gate schemes I, II, III, and IV, respectively.

Then Moldflow software is applied to simulate and analyze the four configurations and compare the corresponding filling times, flow front temperatures, clamping forces, and weld line filling results. Finally, the optimal gate position can be determined, which can reduce the mold revising expenses and improve the quality of the parts.

2.2.1. Filling Time. In the injection molding process, the filling time is defined as the required time for the molten plastic to fill the whole cavity. In this regard, Moldflow is used to analyze the four configurations. Figure 4 shows the filling time of different schemes.

2.2.2. Flow Front Temperature. The flow front temperature is defined as the temperature of the intermediate material flow when the molten plastic is filled to a certain node. This temperature can be considered as the intermediate temperature of the section [11]. Figure 5 presents contours of the flow front temperature for different gate configurations.

2.2.3. Clamping Force. The maximum clamping force exerted on the mold by the injection molding machine is called the clamping force [12]. Figure 6 shows the clamping force of different gate configurations.

2.2.4. The Welding Line. In order to ensure the appropriate appearance and good strength of the molded plastic part, the number and length of the welding lines should be minimized. Moreover, the welding wires are not allowed in places with stress concentration or visible areas [13]. Figure 7 shows the welding wiring of different gate configurations.

The simulation results of filling time, flow front temperature, clamping force, and weld line of the four configurations are summarized in Table 1.

It is found that configuration 4 with four gates has the lowest clamping force, so this gate position is selected as the optimal configuration.

2.3. Simulation and Analysis of Injection Molding Process of the Automobile Instrument Light Guide Bracket. After determining the material, gate position, main channel, shunt channel, and cooling system of the automobile instrument 


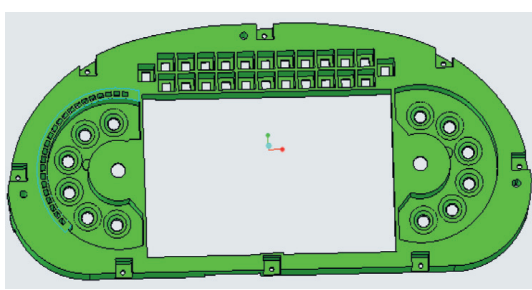

(a)

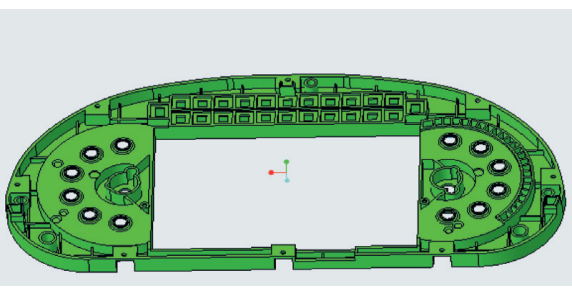

(b)

Figure 1: 3D model of automobile instrument light guide bracket: (a) front view and (b) the reverse view.

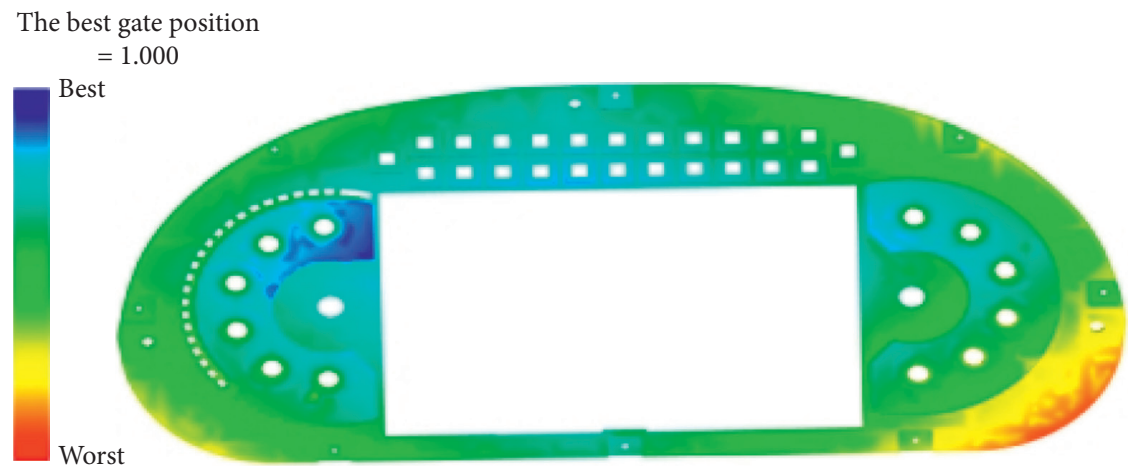

Figure 2: Cloud chart of optimal gate matching.

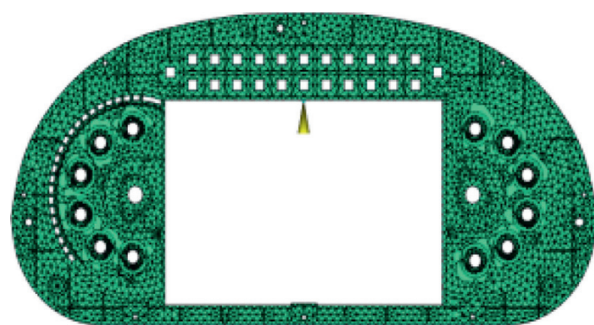

(a)

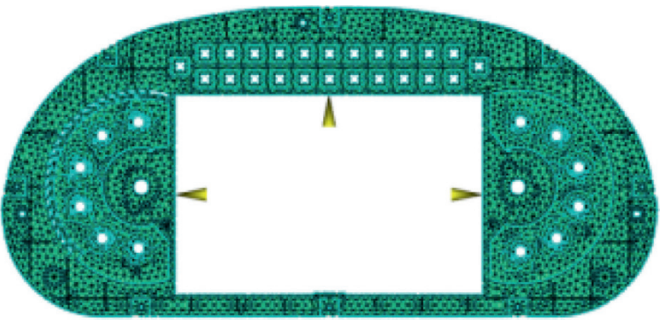

(c)

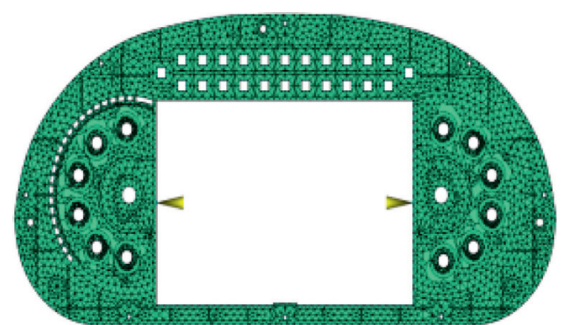

(b)

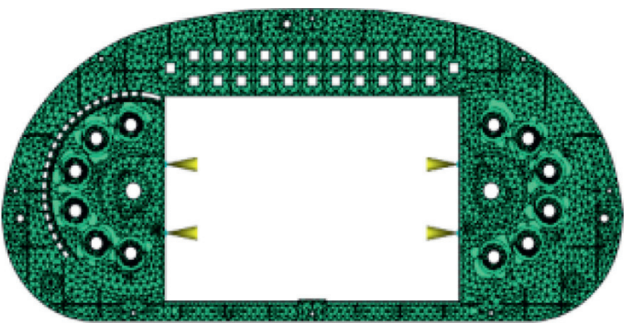

(d)

Figure 3: Configurations of four gate locations.

light guide, the molding process parameters are set to analyze the molded product. Figures 8 and 9 show contours of the volume shrinkage rate and the warping, respectively.

It is observed that the volume shrinkage rate of the edge part is large, and the volume shrinkage rate is small near the sprue. This is because the edge is far from the sprue position, leading to a weak packing pressure. The performed analysis shows that the maximum volume shrinkage rate and warping are $11.82 \%$ and $2.081 \mathrm{~mm}$, respectively.

\section{Design of the Taguchi Orthogonal Experiment of the Molding Process Parameter}

During the injection molding process, many factors affect the part warpage. Studies show that, among all affecting parameters, the molding parameter is one of the important factors. Generally, the process parameters can be optimized by performing a continuous trial and repair process on the 
Filling time
$=1.444(\mathrm{~s})$

(s)

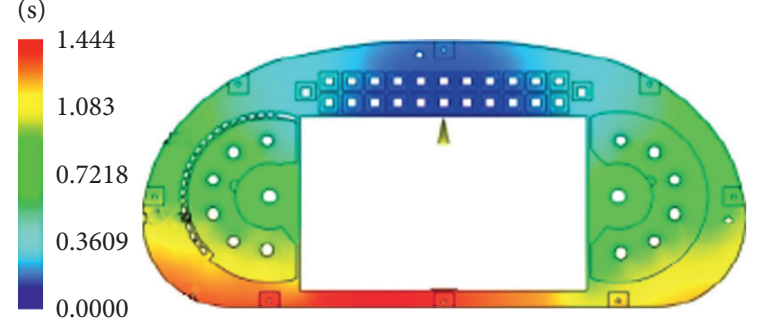

(a)

Filling time

(s)

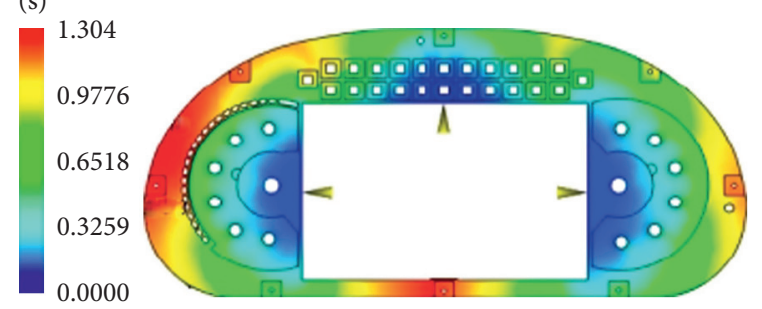

(c)
Filling time
$=1.291(\mathrm{~s})$

(s)

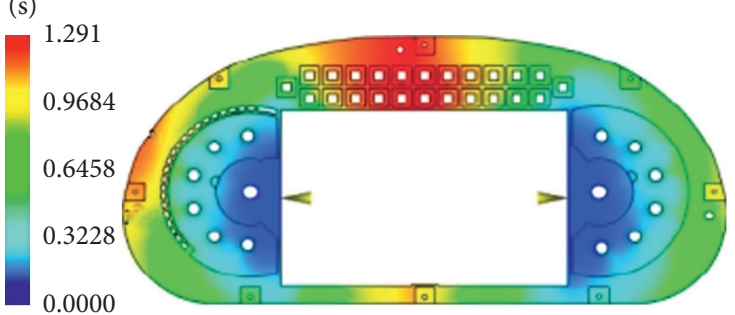

(b)

Filling time

$(\mathrm{s})$

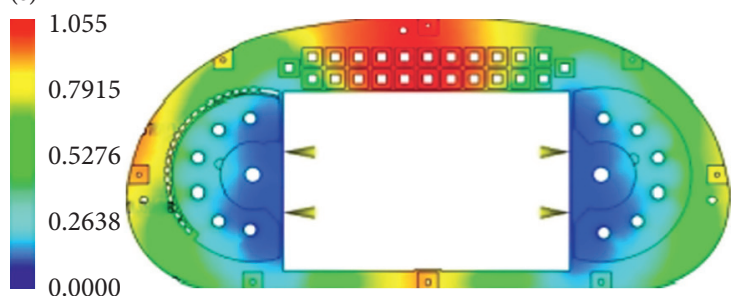

(d)

FIgURE 4: Filling times of the part with different gate locations.

Flow front temperature

$$
=268.6\left({ }^{\circ} \mathrm{C}\right)
$$

$\left({ }^{\circ} \mathrm{C}\right)$

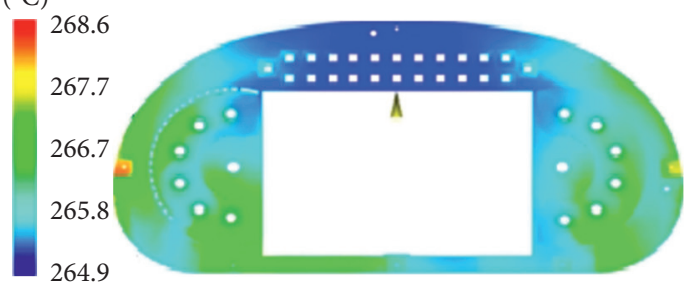

(a)

Flow front temperature

$$
=266.0\left({ }^{\circ} \mathrm{C}\right)
$$

$\left({ }^{\circ} \mathrm{C}\right)$

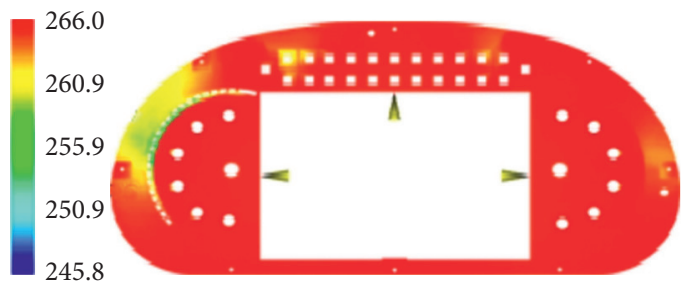

(c)
Flow front temperature

$$
=266.6\left({ }^{\circ} \mathrm{C}\right)
$$

$\left({ }^{\circ} \mathrm{C}\right)$

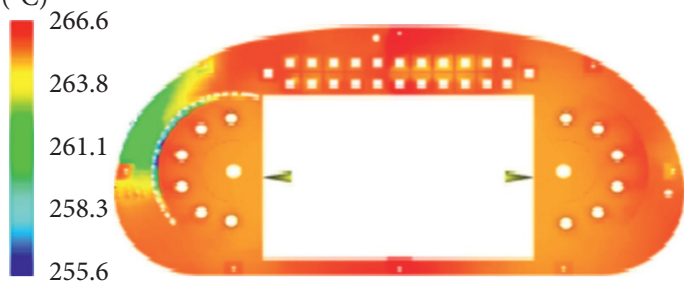

(b)

Flow front temperature

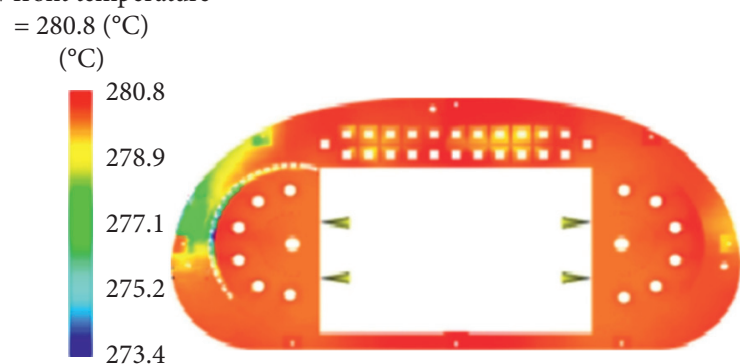

(d)

FIgURE 5: Flow front temperature of four gate configurations.

die, which cannot meet the requirements of modern designs [14]. In this section, it is intended to use the Taguchi orthogonal experimental design method to study the influence of molding parameters on volume shrinkage rate and warping, thereby optimizing the parameters.
3.1. Design of Taguchi Orthogonal Test for Automobile Instrument Conduit Bracket. Taguchi orthogonal test index refers to the effects that should be considered during the test. The volume shrinkage rate and the bracket warping are the main influencing factors on the product surface quality and 


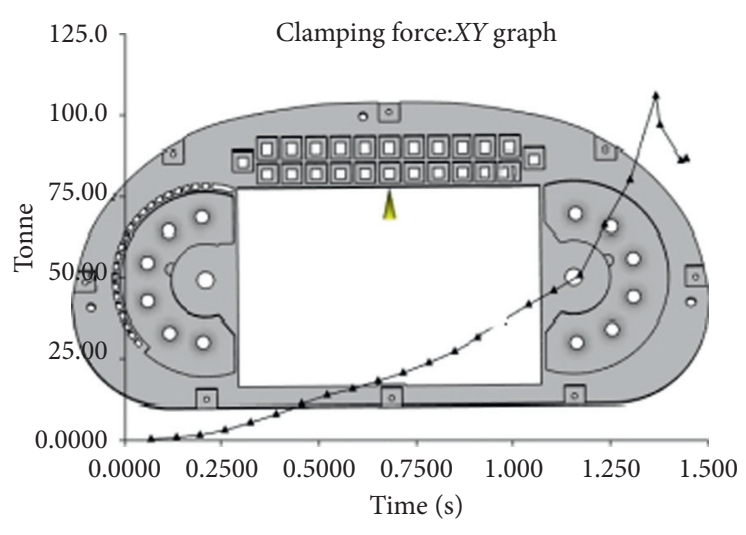

(a)

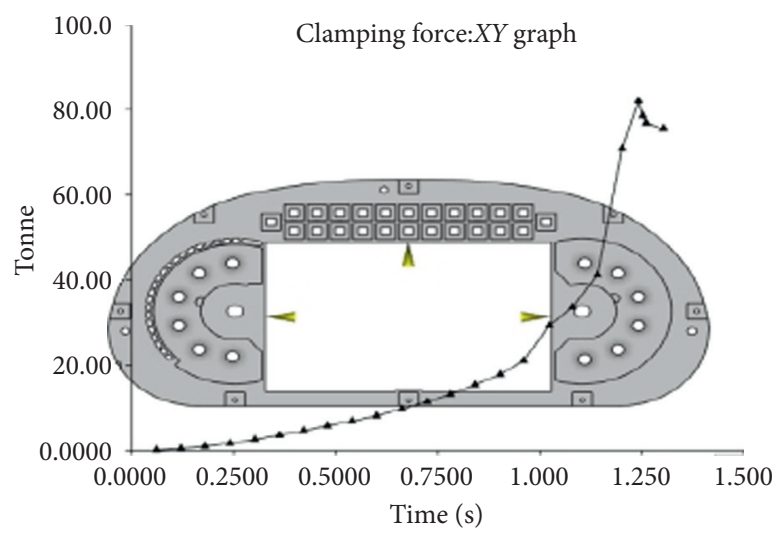

(c)

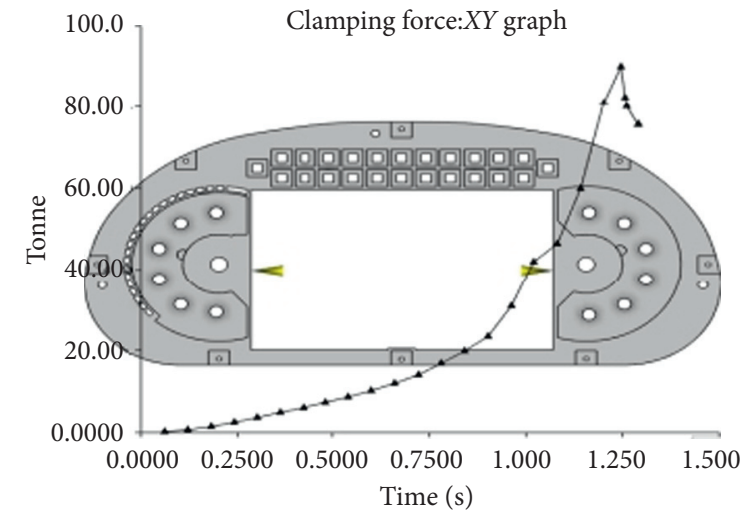

(b)

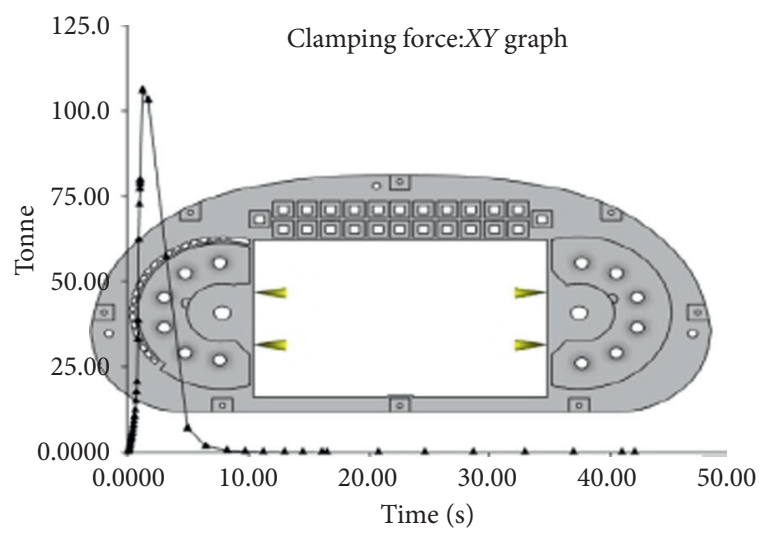

(d)

Figure 6: Clamping force of different gate configurations.

Welding line

$=135.0\left({ }^{\circ} \mathrm{C}\right)$

$\left({ }^{\circ} \mathrm{C}\right)$

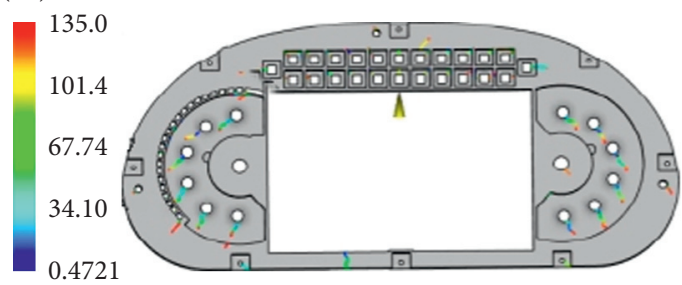

(a)

Welding line

$=135.0\left({ }^{\circ} \mathrm{C}\right)$

$\left({ }^{\circ} \mathrm{C}\right)$

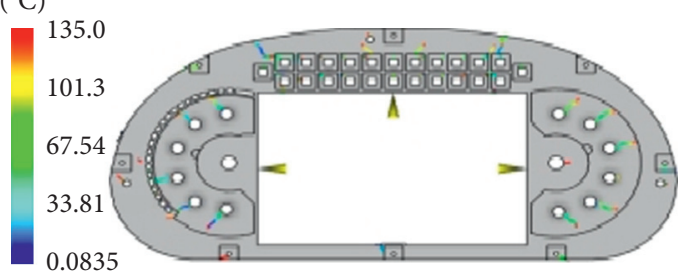

(c)
Welding line

$=135.0\left({ }^{\circ} \mathrm{C}\right)$

$\left({ }^{\circ} \mathrm{C}\right)$

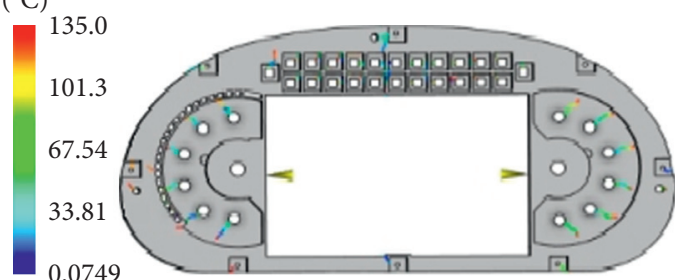

(b)

Welding line

$=135.0\left({ }^{\circ} \mathrm{C}\right)$

$\left({ }^{\circ} \mathrm{C}\right)$

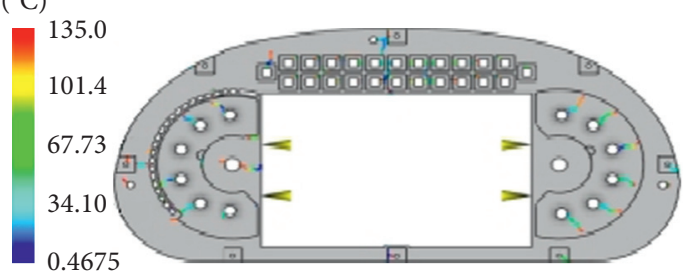

(d)

FIgURE 7: Welding line of different gate configurations. 
TABLE 1: Simulation results of the four configurations.

\begin{tabular}{|c|c|c|c|c|}
\hline Gate number/a & Filling time/s & $\begin{array}{l}\text { Temperature difference } \\
\text { at the flow front } /{ }^{\circ} \mathrm{C}\end{array}$ & Clamping force $/ \mathrm{kN}$ & Characteristics of welding line \\
\hline I & 1.444 & 3.7 & 1059 & \multirow{2}{*}{ The number of pieces is more and the length is larger } \\
\hline II & 1.291 & 11 & 907 & \\
\hline III & 1.304 & 20.2 & 821.2 & \multirow{2}{*}{ The number is less and the distribution is reasonable } \\
\hline IV & 1.055 & 7.4 & 1060 & \\
\hline
\end{tabular}

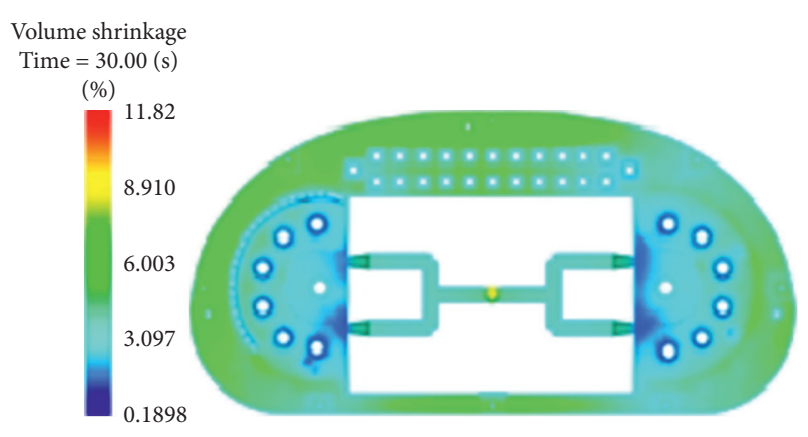

Figure 8: Volume shrinkage contour.

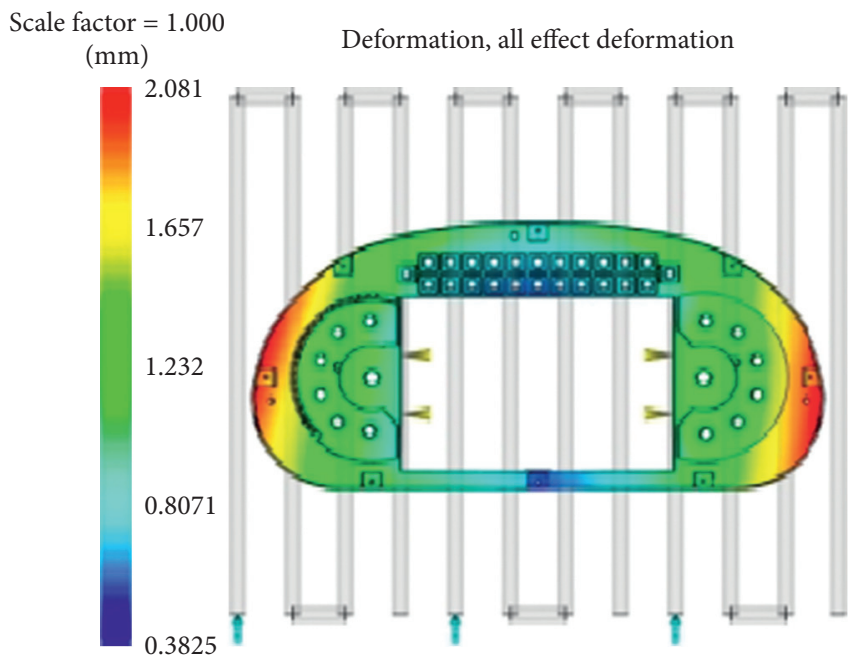

FIgURE 9: Warpage quantity contour.

assembly precision. Therefore, these two quality evaluation indices are selected as the testing indicators.

Test factors are parameters that have a certain influence on the test indices [15]. It is worth noting that the setting of molding parameters is the main factor that affects the volume shrinkage rate and the bracket warpage. Among all molding parameters, the mold temperature, melt temperature, cooling time, packing pressure, and packing time have the highest influence on the test indices. Accordingly, these factors are taken as the test factors. The Moldflow analysis results show that the maximum injection pressure required in the filling process is $101.5 \mathrm{MPa}$.

In the present study, these parameters are selected as the experimental factors of the orthogonal table, where each experimental factor takes four levels. Through the Taguchi orthogonal test, it is intended to investigate the influence of molding parameters on the volume shrinkage rate and the amount of warping and obtain the optimal combination of molding parameters corresponding to two groups of experimental indices. Table 2 presents the process parameters in the simulations. Based on the principle of Taguchi's orthogonal test, an orthogonal test table $L_{32}\left(5^{4}\right)$ was established, and combinations of 32 process parameters in the table were analyzed through the Moldflow software. Accordingly, 32 groups of volume shrinkage rate and part warping were obtained, as shown in Table 3.

\subsection{Data Analysis of the Taguchi Orthogonal Test for Light} Guide Bracket of the Automobile Instrument. In this section, the range and variance analysis were carried out on the orthogonal test data of Taguchi. It should be indicated that the influence trend of the test factors on the test indices can be obtained from the range analysis, while the variance analysis yields the influence degree of the former on the latter parameters [16].

The obtained parameters by the Taguchi orthogonal test are the optimal parameter factors, and the ratio between the main effect and error effect is the signal-to-noise ratio, which can be calculated through the following expression:

$$
\eta=\frac{S}{N}
$$

where $\eta, S$, and $N$ are the signal-to-noise ratio, main effect of the factor, and the error effect, respectively.

Since the combination of signal-to-noise ratio and different response characteristics will produce different results, different signal-to-noise ratio expressions can be defined [17]. Then the signal-to-noise ratio of the small feature is calculated through the following expression:

$$
\eta=-10 \log \left(\frac{1}{n} \sum_{i=1}^{n} y_{i}^{2}\right) .
$$

The two test indices of the bracket are analyzed by the signal-to-noise ratio. The smaller the test index, the better. Combined with the signal-to-noise ratio expression, it is a subtraction function. Therefore, the data in Table 4 can be obtained by substituting the index values into equation (2) by adopting its signal-to-noise ratio with small expected characteristics.

For range analysis, in order to investigate the influence trend of various molding process parameters on the test indices, presented data in Table 4 are processed to obtain the mean value of the signal-to-noise ratio of each index. Table 5 presents the obtained results in this regard. 
TABLE 2: Level factor setting.

\begin{tabular}{lccccc}
\hline & & \multicolumn{2}{c}{ Factors } \\
Levels & $A$ & $B$ & $C$ & $D$ & $\begin{array}{c}D \\
\text { Cooling time/s }\end{array}$ \\
& Mold temperature $/{ }^{\circ} \mathrm{C}$ & Melt temperature $/{ }^{\circ} \mathrm{C}$ & 10 & 40 & 5 \\
Packing pressure/MPa & Packing time/s \\
\hline 1 & 55 & 250 & 15 & 50 & 10 \\
2 & 65 & 260 & 20 & 60 & 70 \\
3 & 75 & 270 & 25 & 20 \\
\hline
\end{tabular}

TABLE 3: Orthogonal design and results.

\begin{tabular}{|c|c|c|c|c|c|c|c|}
\hline \multirow{2}{*}{ Test number } & \multicolumn{5}{|c|}{ Factors } & \multicolumn{2}{|c|}{ Indexes } \\
\hline & $A$ & $B$ & $C$ & $D$ & $E$ & Shrinkage rate $(\%)$ & Amount of warping $(\mathrm{mm})$ \\
\hline 1 & 55 & 250 & 10 & 40 & 5 & 10.81 & 2.081 \\
\hline 2 & 55 & 260 & 15 & 50 & 10 & 8.19 & 1.991 \\
\hline 3 & 55 & 270 & 20 & 60 & 15 & 7.68 & 1.936 \\
\hline 4 & 55 & 280 & 25 & 70 & 20 & 7.493 & 1.905 \\
\hline 5 & 65 & 250 & 10 & 50 & 10 & 7.740 & 2.029 \\
\hline 6 & 65 & 260 & 15 & 40 & 5 & 11.35 & 2.002 \\
\hline 7 & 65 & 270 & 20 & 70 & 20 & 7.105 & 1.930 \\
\hline 8 & 65 & 280 & 25 & 60 & 15 & 8.261 & 1.991 \\
\hline 9 & 75 & 250 & 15 & 60 & 20 & 6.758 & 1.991 \\
\hline 10 & 75 & 260 & 10 & 70 & 15 & 7.710 & 1.952 \\
\hline 11 & 75 & 270 & 25 & 40 & 10 & 12.01 & 1.951 \\
\hline 12 & 75 & 280 & 20 & 50 & 5 & 12.56 & 1.850 \\
\hline 13 & 85 & 250 & 15 & 70 & 15 & 6.950 & 1.978 \\
\hline 14 & 85 & 260 & 10 & 60 & 20 & 7.662 & 1.954 \\
\hline 15 & 85 & 270 & 25 & 50 & 5 & 12.01 & 1.883 \\
\hline 16 & 85 & 280 & 20 & 40 & 10 & 12.55 & 1.931 \\
\hline 17 & 55 & 250 & 25 & 40 & 20 & 6.756 & 2.025 \\
\hline 18 & 55 & 260 & 20 & 50 & 15 & 7.368 & 1.992 \\
\hline 19 & 55 & 270 & 15 & 60 & 10 & 9.315 & 1.921 \\
\hline 20 & 55 & 280 & 10 & 70 & 5 & 12.56 & 1.712 \\
\hline 21 & 65 & 250 & 25 & 50 & 15 & 6.984 & 2.018 \\
\hline 22 & 65 & 260 & 20 & 40 & 20 & 7.000 & 1.985 \\
\hline 23 & 65 & 270 & 15 & 70 & 5 & 12.00 & 1.784 \\
\hline 24 & 65 & 280 & 10 & 60 & 10 & 12.56 & 1.893 \\
\hline 25 & 75 & 250 & 20 & 60 & 5 & 10.81 & 1.958 \\
\hline 26 & 75 & 260 & 25 & 70 & 10 & 8.730 & 1.928 \\
\hline 27 & 75 & 270 & 10 & 40 & 15 & 8.565 & 1.962 \\
\hline 28 & 75 & 280 & 15 & 50 & 20 & 7.963 & 1.938 \\
\hline 29 & 85 & 250 & 20 & 70 & 10 & 8.242 & 1.968 \\
\hline 30 & 85 & 260 & 25 & 60 & 5 & 11.37 & 1.885 \\
\hline 31 & 85 & 270 & 10 & 50 & 20 & 8.293 & 1.948 \\
\hline 32 & 85 & 280 & 15 & 40 & 15 & 8.354 & 1.937 \\
\hline
\end{tabular}

$A$ is the mold temperature, $B$ is the melt temperature, $C$ denotes the cooling time, $D$ is the packing pressure, and $E$ is the packing time. Based on the discussed procedure, the signal-to-noise ratio of the minimum feature is adopted. It is worth noting that the larger the signal-to-noise ratio, the smaller the corresponding test index. In other words, the larger the SNR, the smaller the volume shrinkage rate and warpage amount. Table 6 reveals that when the mold temperature, melt temperature, cooling time, packing pressure, and packing time are set to $55^{\circ} \mathrm{C}, 250^{\circ} \mathrm{C}, 15 \mathrm{~s}$, $70 \mathrm{MPa}$, and $20 \mathrm{~s}$ (hereafter called A1B1C2D4E4 parameters), the average shrinkage of the signal-to-noise ratio is the highest, while the volume shrinkage is the minimum. On the other hand, when these parameters are set to $85^{\circ} \mathrm{C}, 280^{\circ} \mathrm{C}$, $10 \mathrm{~s}, 70 \mathrm{MPa}$, and $5 \mathrm{~s}$ (hereafter called A4B4C1D4E1 parameters), the average warpage of the signal-to-noise ratio is the largest, while the warpage amount is the minimum. Then the combination of these two groups of parameters is simulated and analyzed through the Moldflow software. Obtained results are shown in Figures 10 and 11.

Figures 10 and 11 show that the minimum volume shrinkage rate for $A 1 B 1 C 2 D 4 E 4$ parameters is $6.721 \%$ and the minimum amount of warping for $A 4 B 4 C 1 D 4 E 1$ parameters is 1.763 . 
TABLE 4: Signal-to-noise ratio of volume shrinkage rate and amount of warping.

\begin{tabular}{|c|c|c|}
\hline \multirow[t]{2}{*}{ Test number } & \multicolumn{2}{|c|}{$\begin{array}{l}\text { Signal-to-noise ratio of volume shrinkage rate and } \\
\text { amount of warping. }\end{array}$} \\
\hline & $\mathrm{S} / \mathrm{N}$ shrinkage rate/\% & $\mathrm{S} / \mathrm{N}$ amount of warping $/ \mathrm{mm}$ \\
\hline 1 & -20.677 & -6.365 \\
\hline 2 & -18.266 & -5.981 \\
\hline 3 & -17.707 & -5.738 \\
\hline 4 & -17.493 & -5.598 \\
\hline 5 & -17.775 & -6.146 \\
\hline 6 & -21.100 & -6.029 \\
\hline 7 & -17.031 & -5.711 \\
\hline 8 & -18.341 & -5.981 \\
\hline 9 & -16.584 & -5.981 \\
\hline 10 & -17741 & -5.810 \\
\hline 11 & -21.591 & -5.805 \\
\hline 12 & -21.980 & -5.343 \\
\hline 13 & -16.840 & -5.925 \\
\hline 14 & -17.687 & -5.818 \\
\hline 15 & -21.591 & -5.497 \\
\hline 16 & -21.973 & -5.716 \\
\hline 17 & -16.594 & -6.129 \\
\hline 18 & -17.347 & -5.986 \\
\hline 19 & -19.384 & -5.671 \\
\hline 20 & -21.980 & -4.670 \\
\hline 21 & -16.882 & -6.098 \\
\hline 22 & -16.902 & -5.955 \\
\hline 23 & -21.584 & -5.028 \\
\hline 24 & -21.980 & -5.543 \\
\hline 25 & -20.676 & -5.836 \\
\hline 26 & -18.820 & -5.702 \\
\hline 27 & -18.655 & -5.854 \\
\hline 28 & -18.022 & -5.747 \\
\hline 29 & -18.321 & -5.881 \\
\hline 30 & -21.115 & -5.506 \\
\hline 31 & -18.374 & -5.792 \\
\hline 32 & -18.438 & -5.743 \\
\hline
\end{tabular}

For analysis of variance, the influence trend of test factors on indices was processed by analysis of variance [18]. This analysis is conducted in five steps as follows:

(1) Calculate the sum of partial squares of each test factor through the following expression:

$$
S_{a}=\sum_{i=1}^{n}\left(\bar{I}_{j}-\bar{Y}\right)^{2},
$$

where $\bar{I}_{j}$ and $\bar{Y}$ are the mean signal-to-noise ratio of the volume shrinkage rate at a certain level of a test factor $\bar{Y}$ and the signal-to-noise ratio of volume shrinkage rate at all levels of all test factors which was taken as the mean value, respectively.

(2) Calculate the sum of squares of the total deviation:

$$
S_{e}=\sum_{i=1}^{n} S_{a i} \text {, }
$$

where $S_{a i}$ is the partial sum of squares of a test factor.

(3) Calculate the degree of freedom of test factors:

$$
f_{a}=g-1
$$

(4) Calculate the sum of squares of the average deviation:

$$
\widehat{S}_{a}=\frac{S_{a}}{f_{a}} .
$$

(5) Finally, the influence degree $P$ can be calculated in the following form:

$$
P=\frac{S_{a}}{S_{e}} \times 100 \% .
$$

For each factor, the ratio of the sum of squares of deviations to the sum of squares of total deviations in the analysis of variance reflects the influence of the processing parameters on the test indices [19]. $\bar{I}_{j}$ is the mean signal-tonoise ratio of the volume shrinkage rate at a certain level of a test factor; $\bar{Y}$ is the signal-to-noise ratio of volume shrinkage rate at all levels of all test factors which was taken as the mean value. Similarly, the mean value of the signal-to-noise ratio of warpage amount can be obtained. Table 6 presents the obtained results from the variance analysis.

Table 6 shows that, among the studied parameters, packing time has the greatest influence on the volume shrinkage rate and accounts for about $75.2 \%$ of the total shrinkage rate. It is found that as the packing time increases, the volume shrinkage rate gradually decreases. On the other hand, the melt temperature has a greater influence on the volume shrinkage rate, and as the melt temperature decreases, the volume shrinkage rate gradually decreases too. Moreover, the effects of the mold temperature, cooling time, and packing pressure on the volume shrinkage rate are almost the same. The higher the mold temperature, the greater the volume shrinkage rate. The volume shrinkage rate decreases first and then increases with the increase of the cooling time. As the packing pressure increases, the volume shrinkage rate fluctuates.

It is also found that the cooling time is the most important factor to the warpage amount. With the increase of the cooling time, the warpage amount increases first and then decreases. The second effective factor is the melt temperature, accounting for $24.29 \%$ of the warpage amount. When the melt temperature increases, the warpage amount decreases gradually. The influences of the packing pressure and packing time on the warpage amount are similar, accounting for $14.33 \%$ and $12.66 \%$ of the warpage amount, respectively. When the packing pressure increases, the warpage amount gradually decreases. Meanwhile, when the packing time increases, the warpage amount first increases and then decreases. Table 6 indicates that the die temperature has the lowest influence on the warpage amount. When the mold temperature increases gradually, the warpage amount first increases and then decreases.

Based on the Taguchi orthogonal test design, the influence degree of various molding parameters on volume shrinkage rate and warpage amount can be obtained. Accordingly, the optimal combination of molding parameters 
TABLE 5: Mean signal-to-noise ratio of shrinkage and warpage.

\begin{tabular}{|c|c|c|c|c|c|c|}
\hline Optimization objective & Mean & $A$ & $B$ & C & $D$ & $E$ \\
\hline Shrinkage rate & $\begin{array}{l}\bar{I}_{1} \\
\bar{I}_{2} \\
\bar{I}_{3} \\
\bar{I}_{4} \\
\bar{Y} \\
\end{array}$ & $\begin{array}{l}-18.681 \\
-18.949 \\
-19.259 \\
-19.292\end{array}$ & $\begin{array}{l}-18.044 \\
-18.622 \\
-19.490 \\
-20.026\end{array}$ & $\begin{array}{l}-19.359 \\
-18.717 \\
-18.992 \\
-19.053 \\
-19.004 \\
\end{array}$ & $\begin{array}{l}-19.491 \\
-18.780 \\
-19.184 \\
-18.726\end{array}$ & $\begin{array}{l}-21.338 \\
-19.764 \\
-17.744 \\
-17.336\end{array}$ \\
\hline Amount of warping & $\begin{array}{l}\bar{J}_{1} \\
\bar{J}_{2} \\
\bar{J}_{3} \\
\bar{J}_{4} \\
\bar{X}\end{array}$ & $\begin{array}{l}-5.767 \\
-5.811 \\
-5.76 \\
-5.735\end{array}$ & $\begin{array}{l}-6.045 \\
-5.848 \\
-5.637 \\
-5.543\end{array}$ & $\begin{array}{l}-5.750 \\
-5.763 \\
-5.771 \\
-5.189 \\
-5.738 \\
\end{array}$ & $\begin{array}{l}-5.949 \\
-5.824 \\
-5.759 \\
-5.541\end{array}$ & $\begin{array}{l}-5.534 \\
-5.806 \\
-5.892 \\
-5.841\end{array}$ \\
\hline
\end{tabular}

TABLE 6: Results of the variance analysis.

\begin{tabular}{|c|c|c|c|c|c|}
\hline $\begin{array}{l}\text { Optimization } \\
\text { objective }\end{array}$ & $\begin{array}{l}\text { Sources of } \\
\text { variance }\end{array}$ & $\begin{array}{c}\text { Sum of squares of } \\
\text { deviations/Sa }\end{array}$ & $\begin{array}{l}\text { Degrees of } \\
\text { freedom } / \mathrm{fa}\end{array}$ & $\begin{array}{c}\text { The mean square } \\
\text { value } / S_{a}\end{array}$ & $\begin{array}{c}\text { Influence degree } P \\
(\%)\end{array}$ \\
\hline \multirow{6}{*}{ Shrinkage rate } & $A$ & 0.255 & 3 & 0.085 & 1.84 \\
\hline & $B$ & 2.584 & 3 & 0.861 & 18.69 \\
\hline & C & 0.211 & 3 & 0.070 & 1.53 \\
\hline & $D$ & 0.378 & 3 & 0.126 & 2.73 \\
\hline & $E$ & 10.395 & 3 & 3.465 & 75.2 \\
\hline & $\mathrm{Se}$ & 13.823 & 15 & & \\
\hline \multirow{6}{*}{ Amount of warping } & $A$ & 0.0067 & 3 & 0.0022 & 1.05 \\
\hline & $B$ & 0.1546 & 3 & 0.0515 & 24.29 \\
\hline & $C$ & 0.3033 & 3 & 0.1011 & 47.66 \\
\hline & $D$ & 0.0912 & 3 & 0.0304 & 14.33 \\
\hline & $E$ & 0.0806 & 3 & 0.0269 & 12.66 \\
\hline & $\mathrm{Se}$ & 0.6364 & 15 & & \\
\hline
\end{tabular}

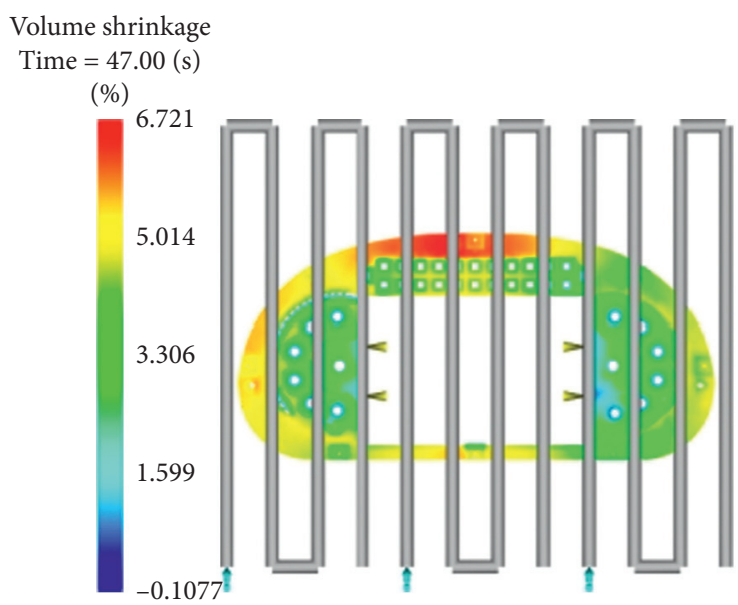

(a)
Scaling factor $=1.000 \quad$ Deformation, all effect deformation

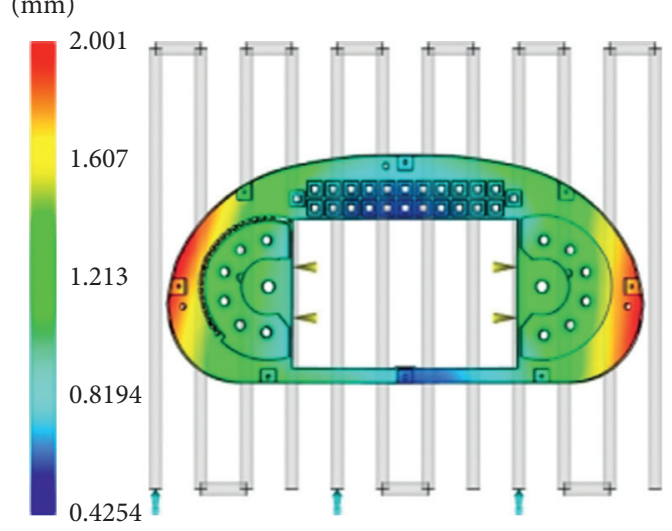

(b)

Figure 10: Analysis results for $A 1 B 1 C 2 D 4 E 4$ parameters.

can be obtained to minimize the volume shrinkage rate and the warpage amount.

\subsection{Multiobjective Optimization of Grey Correlation Analysis.} The foregoing discussions demonstrate that range and variance processing are effective methods to analyze and optimize a single factor. However, these methods cannot be applied to optimize multiple objectives at the same time. In this regard, grey correlation analysis is often used in the data processing of the Taguchi orthogonal test, which can transform a multiobjective problem into a single-objective problem so that it is beneficial to analyze the test data.

The basic principle of the grey correlation analysis is to determine the degree of correlation according to the similarity degree of the curve geometry for each factor. The more similar the curve geometries, the higher the correlation degree between factors. 


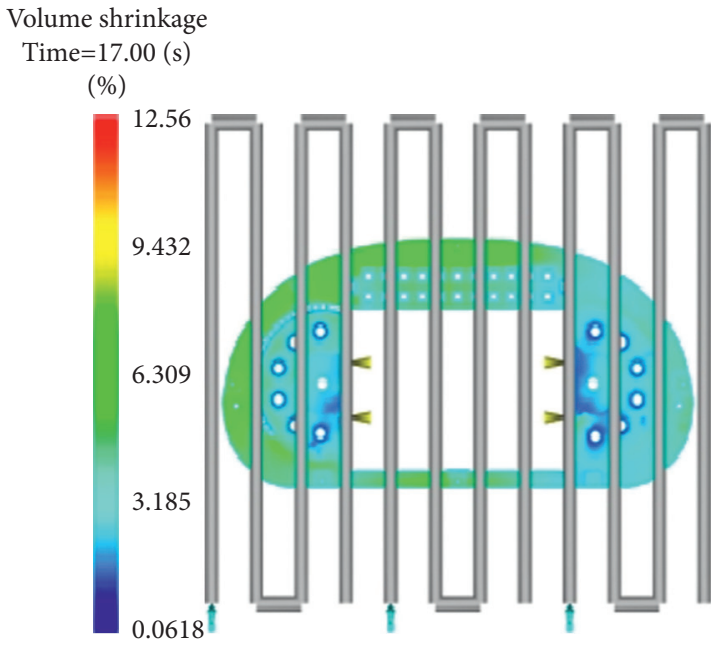

(a) $\begin{gathered}\text { Scaling factor } \\ (\mathrm{mm})\end{gathered}=1.000 \quad$ Deformation, all effect deformation

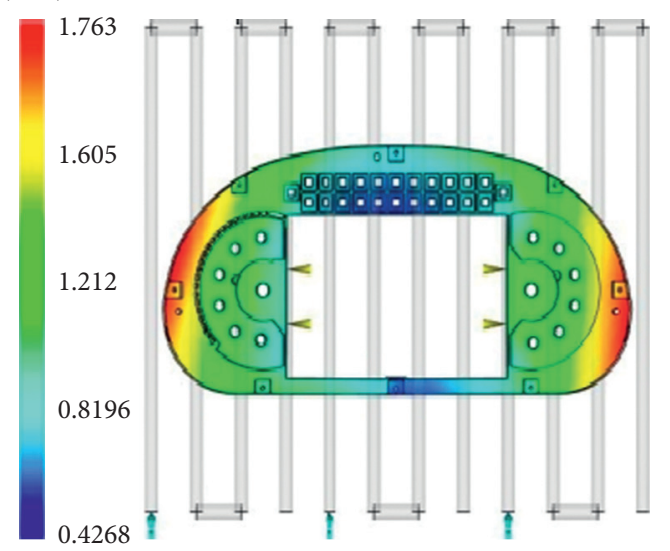

(b)

Figure 11: Analysis results for $A 4 B 4 C 1 D 4 E 1$ parameters.

3.3.1. Evaluation Index Data Matrix. Based on the objective analysis, the evaluation index matrix can be established with evaluation indices. This matrix can be expressed in the following form:

$$
A=\left[\begin{array}{cccccc}
X_{1}(1) & X_{1}(2) & \ldots & X_{1}(j) & \ldots & X_{1}(m) \\
X_{2}(1) & X_{2}(2) & \ldots & X_{2}(j) & \ldots & X_{2}(m) \\
\ldots & \ldots & \ldots & \ldots & \ldots & \ldots \\
X_{i}(1) & X_{i}(2) & \ldots & X_{i}(j) & \ldots & X_{i}(m) \\
\ldots & \ldots & \ldots & \ldots & \ldots & \ldots \\
X_{n}(1) & X_{n}(2) & \ldots & X_{n}(j) & \ldots & X_{n}(m)
\end{array}\right],
$$

where $n$ is the number of tests, $m$ is the number of evaluation indices, and $x_{i}(j)$ is the raw data.

3.3.2. Normalizing the Evaluation Target Data. In order to ensure the equivalence of each index, it is necessary to normalize the original sequence to eliminate its dimension. In the present study, the normalization is carried out through the following expression:

$$
X_{i}^{*}(k)=\frac{\max X_{i \forall j}(j)-X_{i}(j)}{\max X_{i \forall j}(j)-\min X_{i \forall j}(j)},
$$

where $x_{i}^{*}(k)$ denotes the index value after normalization, $\max X_{i \forall j}(j)$ is the maximum value of columns in the data matrix of evaluation index, $\min X_{i \forall j}(j)$ is the minimum value of columns in the data matrix of evaluation index, $x_{i}(j)$ is a vector in the data matrix of evaluation index, and $X_{o b}(j)$ is the target value of $X_{i}(j)$.

\subsubsection{Determination of the Grey Correlation Coefficient} Matrix. The maximum value of each index can be considered as the reference sequence.

$$
\begin{aligned}
K & =,\left(k_{1}, k_{2}, k_{3}, \ldots, k_{j}, \ldots k_{m}\right), \\
k_{j} & =\max \left(X_{i}(j), X_{2}(j), \ldots, X_{j}(j), \ldots, X_{n}(j)\right), \\
\xi_{i} & =\frac{\min (\Delta \min )+\rho \bullet \max (\Delta \max )}{\Delta_{0, i}(j)+\rho \bullet \max (\Delta \max )},
\end{aligned}
$$

where $\Delta_{0, i}(j)=\left|k_{j}-X_{i}(j)\right|$ is the absolute value of the reference sequence and comparison sequence, $\min (\Delta \min )=\min \left(\min \left|k_{j}-X_{i}(j)\right|\right)$ is the minimum absolute value of each reference sequence and the comparison sequence, $\max (\Delta \max )=\max \left(\max \left|k_{j}-X_{i}(j)\right|\right)$ denotes the maximum absolute value of each reference sequence and comparison sequence, $\xi_{i}$ is the correlation coefficient of each evaluation index, and $\rho$ is the resolution coefficient, which is usually set to 0.5 [20].

Accordingly, the grey correlation coefficient matrix can be established in the following form:

$$
\xi=\left[\begin{array}{llll}
\xi_{11} & \xi_{12} & \ldots & \xi_{1 m} \\
\xi_{21} & \xi_{22} & \ldots & \xi_{2 m} \\
\ldots & \ldots & \ldots & \ldots \\
\xi_{n 1} & \xi_{n 2} & \ldots & \xi_{n m}
\end{array}\right]
$$

\subsubsection{Determination of the Grey Correlation Degree.}

$$
\gamma_{i}=\frac{1}{m} \sum_{j=1}^{m} \xi_{i j}, \quad(i=1,2, \ldots, n) .
$$

For evaluation of the grey correlation degree of automobile instrument light guide bracket, the grey correlation degree of volume shrinkage rate and warpage amount can be obtained from equations (8) to (12), respectively. Then the multiobjective problem can be transformed into a single- 
TABLe 7: Evaluation index matrix, correlation coefficient matrix, and grey correlation degree.

\begin{tabular}{|c|c|c|c|c|c|c|c|}
\hline \multirow[t]{2}{*}{ Serial number } & \multicolumn{2}{|c|}{$\begin{array}{l}\text { Evaluation index } \\
\text { matrix }\end{array}$} & \multicolumn{2}{|c|}{ Normalized matrix } & \multicolumn{2}{|c|}{$\begin{array}{c}\text { Correlation } \\
\text { coefficient matrix }\end{array}$} & \multirow{2}{*}{$\begin{array}{c}\text { Grey correlation degree } \\
\xi \xi\end{array}$} \\
\hline & $X_{i}(1)$ & $X_{i}(2)$ & $X_{i}^{*}(1)$ & $X_{i}^{*}(2)$ & $\xi_{i 1}$ & $\xi_{i 2}$ & \\
\hline 1 & 10.81 & 2.081 & 0.302 & 0 & 0.417 & 0.333 & 0.375 \\
\hline 2 & 8.19 & 1.991 & 0.753 & 0.244 & 0.669 & 0.398 & 0.5335 \\
\hline 3 & 7.68 & 1.936 & 0.841 & 0.393 & 0.759 & 0.452 & 0.6055 \\
\hline 4 & 7.493 & 1.905 & 0.873 & 0.477 & 0.797 & 0.489 & 0.643 \\
\hline 5 & 7.740 & 2.029 & 0.830 & 0.141 & 0.746 & 0.368 & 0.557 \\
\hline 6 & 11.35 & 2.002 & 0.208 & 0.214 & 0.387 & 0.389 & 0.388 \\
\hline 7 & 7.105 & 1.930 & 0.940 & 0.409 & 0.893 & 0.458 & 0.6755 \\
\hline 8 & 8.261 & 1.991 & 0.741 & 0.244 & 0.659 & 0.398 & 0.5285 \\
\hline 9 & 6.758 & 1.991 & 1 & 0.244 & 1 & 0.398 & 0.699 \\
\hline 10 & 7.710 & 1.952 & 0.836 & 0.350 & 0.753 & 0.435 & 0.594 \\
\hline 11 & 12.01 & 1.951 & 0.095 & 0.352 & 0.356 & 0.436 & 0.396 \\
\hline 12 & 12.56 & 1.850 & 0 & 0.626 & 0.333 & 0.572 & 0.4525 \\
\hline 13 & 6.950 & 1.978 & 0.967 & 0.279 & 0.938 & 0.410 & 0.674 \\
\hline 14 & 7.662 & 1.954 & 0.844 & 0.344 & 0.762 & 0.433 & 0.5975 \\
\hline 15 & 12.01 & 1.883 & 0.095 & 0.537 & 0.356 & 0.519 & 0.4375 \\
\hline 16 & 12.55 & 1.931 & 0.001 & 0.407 & 0.334 & 0.457 & 0.3955 \\
\hline 17 & 6.756 & 2.025 & 1 & 0.152 & 1 & 0.371 & 0.6855 \\
\hline 18 & 7.368 & 1.992 & 0.895 & 0.241 & 0.826 & 0.397 & 0.6115 \\
\hline 19 & 9.315 & 1.921 & 0.559 & 0.434 & 0.531 & 0.469 & 0.5 \\
\hline 20 & 12.56 & 1.712 & 0 & 1 & 0.333 & 1 & 0.6665 \\
\hline 21 & 6.984 & 2.018 & 0.961 & 0.171 & 0.928 & 0.376 & 0.625 \\
\hline 22 & 7.000 & 1.985 & 0.958 & 0.260 & 0.923 & 0.403 & 0.663 \\
\hline 23 & 12.00 & 1.784 & 0.096 & 0.805 & 0.356 & 0.719 & 0.5375 \\
\hline 24 & 12.56 & 1.893 & 0 & 0.509 & 0.333 & 0.505 & 0.419 \\
\hline 25 & 10.81 & 1.958 & 0.302 & 0.333 & 0.417 & 0.428 & 0.4225 \\
\hline 26 & 8.730 & 1.928 & 0.660 & 0.415 & 0.595 & 0.461 & 0.528 \\
\hline 27 & 8.565 & 1.962 & 0.688 & 0.322 & 0.616 & 0.424 & 0.52 \\
\hline 28 & 7.963 & 1.938 & 0.792 & 0.388 & 0.706 & 0.450 & 0.578 \\
\hline 29 & 8.242 & 1.968 & 0.744 & 0.306 & 0.661 & 0.419 & 0.54 \\
\hline 30 & 11.37 & 1.885 & 0.205 & 0.531 & 0.386 & 0.516 & 0.451 \\
\hline 31 & 8.293 & 1.948 & 0.735 & 0.360 & 0.654 & 0.439 & 0.5465 \\
\hline 32 & 8.354 & 1.937 & 0.725 & 0.390 & 0.645 & 0.450 & 0.5475 \\
\hline
\end{tabular}

objective problem. Table 7 presents the warpage amount and volume shrinkage rate data based on grey correlation analysis.

For range analysis of the grey correlation degree, the mean value and the corresponding range values can be calculated from the range analysis of the grey correlation degree. Table 8 indicates that the larger the value of the evaluation factor, the stronger the grey correlation and the higher the influence on the evaluation index.

Table 8 indicates that the highest value of the grey correlation degree is obtained when the mold temperature, melt temperature, cooling time, packing pressure, and the packing time are set to $55^{\circ} \mathrm{C}, 250^{\circ} \mathrm{C}, 25 \mathrm{~s}, 70 \mathrm{MPa}$, and $20 \mathrm{MPa}$, respectively. These settings (hereafter called $A 1 B 1 C 4 D 4 E 4)$ have the greatest influence on the volume shrinkage rate and the warpage amount, which is the optimal combination of process parameters. Then these molding parameters are introduced to the Moldflow software and the simulation results are shown in Figure 12.

Figure 12 shows that the grey correlation analysis is an effective scheme to optimize the molding parameters. It is
TABLE 8: Range analysis of the grey correlation degree.

\begin{tabular}{lccccc}
\hline Level & $A$ & $B$ & $C$ & $D$ & $E$ \\
\hline 1 & 0.578 & 0.576 & 0.534 & 0.496 & 0.466 \\
2 & 0.553 & 0.546 & 0.540 & 0.546 & 0.484 \\
3 & 0.524 & 0.527 & 0.546 & 0.528 & 0.592 \\
4 & 0.524 & 0.529 & 0.557 & 0.607 & 0.636 \\
Range & 0.054 & 0.049 & 0.023 & 0.111 & 0.170 \\
\hline
\end{tabular}

Note: $A$ is the mold temperature, $B$ is the melt temperature, $C$ is the cooling time, $D$ is the packing pressure, and $E$ is the packing time.

found that the optimal volume shrinkage rate and warpage amount are $6.753 \%$ and $1.999 \mathrm{~mm}$, respectively.

Based on the performed Taguchi orthogonal test and grey correlation analysis, the optimal molding parameters can be obtained. In this regard, Table 9 presents the optimal results.

Table 9 demonstrates that the Taguchi orthogonal test and the grey correlation analysis are effective ways to optimize the molding process parameters and obtain different quality index values. It is found that the optimal volume shrinkage rate and warpage amount are $6.753 \%$ and $1.999 \%$, respectively. 


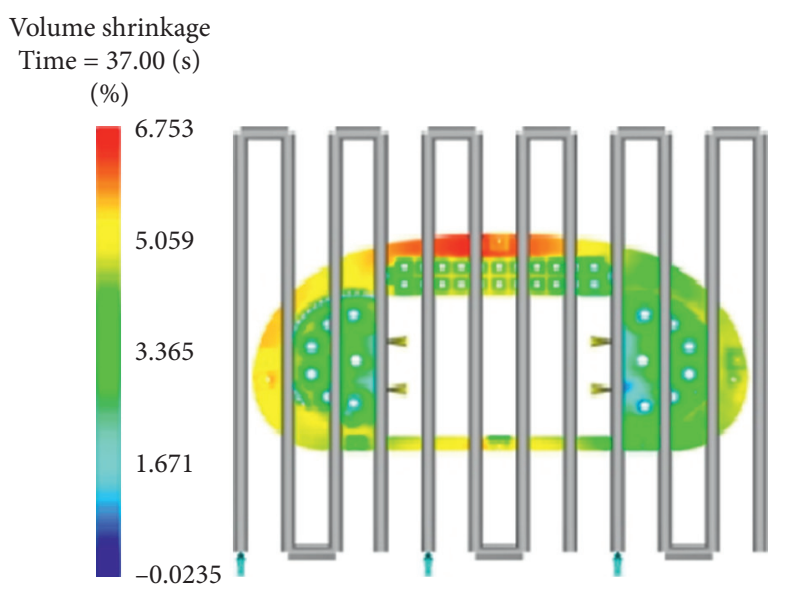

(a)

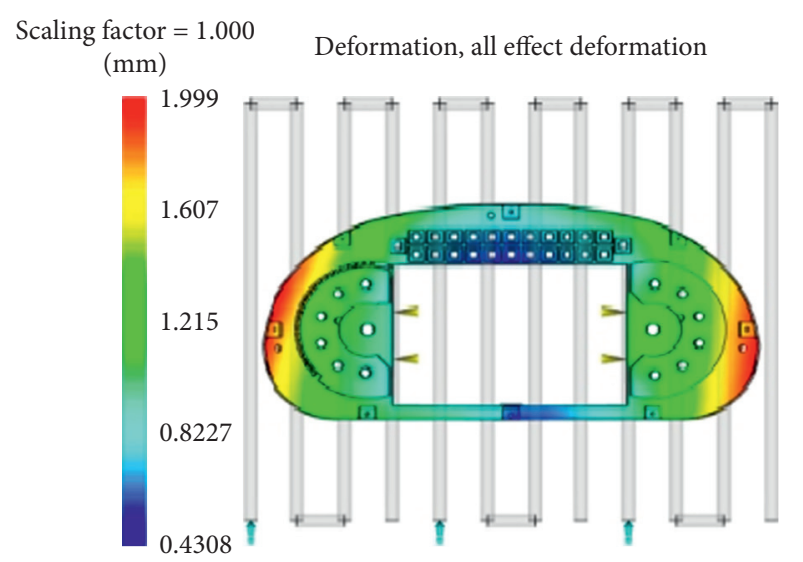

(b)

FIgURE 12: Analysis results of $A 1 B 1 C 4 D 4 E 4$ parameter.

TABLE 9: Comparison of quality evaluation indices of the Taguchi orthogonal test and the grey correlation degree.

\begin{tabular}{lcccc}
\hline Index & Influence factors & $\begin{array}{c}\text { Process parameter } \\
\text { combination }\end{array}$ & $\begin{array}{c}\text { Volume shrinkage } \\
(\%)\end{array}$ & $\begin{array}{c}\text { Amount of warping } \\
(\mathrm{mm})\end{array}$ \\
\hline $\begin{array}{l}\text { Warpage amount analysis based on Taguchi } \\
\text { orthogonal test }\end{array}$ & $C>B>D>E>A$ & $A 1 B 1 C 2 D 4 E 4$ & 6.721 & 2.001 \\
$\begin{array}{l}\text { Volume shrinkage rate analysis based on } \\
\begin{array}{l}\text { Taguchi orthogonal test } \\
\text { Grey correlation analysis }\end{array}\end{array}$ & $E>B>D>A>C$ & $A 4 B 4 C 1 D 4 E 1$ & 12.56 & 1.763 \\
\hline
\end{tabular}

Note: $A$ is mold temperature, $B$ is melt temperature, $C$ is cooling time, $D$ is packing pressure, and $E$ is packing time.

\section{Conclusion}

In the present study, four gate configurations are preliminarily proposed for the injection molding of the automobile light guide bracket. Then numerical simulations are performed through the Moldflow software. Accordingly, filling time, flow front temperature, clamping force, and weld line are analyzed and compared. It is found that, in the best configuration, the filling time is $1.055 \mathrm{~s}$, the temperature difference of flow front is $7.4^{\circ} \mathrm{C}$, the clamping force is $1060 \mathrm{kN}$, the number of welding lines is low, and the weld distribution is reasonable. Finally, volume shrinkage and warpage are calculated as quality evaluation indices through the simulation in the Moldflow software. The obtained results show that the maximum volume shrinkage rate and the maximum warpage amount are $11.82 \%$ and $2.081 \mathrm{~mm}$, respectively.

The volume shrinkage rate and warpage amount of the bracket are selected as experimental evaluation indices, and different molding process parameters such as the mold temperature, melt temperature, cooling time, packing pressure, and packing time are taken as experimental level factors. Then the range analysis of the Taguchi orthogonal test is conducted, where the obtained results show that when the process parameters are set to $A 1 B 1 C 2 D 4 E 4\left(55^{\circ} \mathrm{C}\right.$, $250^{\circ} \mathrm{C}, 15 \mathrm{~s}, 70 \mathrm{MPa}$, and $20 \mathrm{~s}$ ), the mean shrinkage signalto-noise ratio is the maximum and the volume shrinkage is the minimum. Meanwhile, when the process parameters are set to $A 4 B 4 C 1 D 4 E 1\left(85^{\circ} \mathrm{C}, 280^{\circ} \mathrm{C}, 10 \mathrm{~s}, 70 \mathrm{MPa}\right.$, and $\left.5 \mathrm{~s}\right)$, the mean warpage signal-to-noise ratio is the maximum and the warpage is the minimum. Moreover, the minimum volume shrinkage rate for $A 1 B 1 C 2 D 4 E 4$ parameters is $6.721 \%$ and the minimum warpage amount for $A 4 B 4 C 1 D 4 E 1$ parameters is $1.763 \mathrm{~mm}$. Through variance analysis, it is found that the packing time is the molding parameter with the greatest influence on the volume shrinkage rate accounting for about $75.2 \%$ of the total shrinkage rate, and the cooling time has the greatest influence on the warpage amount. The performed simulations reveal that as the cooling time increases, the warpage amount increases first and then decreases. Through the Taguchi orthogonal test design, the influence degree of various molding parameters can be obtained on the volume shrinkage rate and warpage amount.

Finally, the range analysis of the grey correlation is carried out to optimize the volume shrinkage rate and warpage amount simultaneously. Accordingly, it is found that the largest grey correlation can be obtained when the processing parameters are set to $A 1 B 1 C 4 D 4 E 4\left(55^{\circ} \mathrm{C}, 250^{\circ} \mathrm{C}\right.$, $25 \mathrm{~s}, 70 \mathrm{MPa}$, and $20 \mathrm{MPa}$ ). The combination has the greatest influence on the volume shrinkage rate and warpage amount, which is the optimal combination of process parameters. Then the combination of processing parameters is analyzed, and the optimal volume shrinkage rate and warpage amount were obtained as $6.753 \%$ and $1.999 \mathrm{~mm}$, respectively. 


\section{Data Availability}

The data used to support the findings of this study are included within the article.

\section{Conflicts of Interest}

The authors declare that they have no conflicts of interest.

\section{Acknowledgments}

This article belongs to the major projects of the University Synergy Innovation Program of Anhui Province (GXXT2019-004) and the Teaching Research Project of Anhui Education Department (2019jyxm0229).

\section{References}

[1] M. Yan, L. Liu, C. Huang, H. Geng, and X. Han, "CAE analysis of plastic handle based on moldflow," China Shipping (Second Half), vol. 2, no. 1, pp. 131-132, 2009.

[2] X. Li and L. Xiao, "Mould design and NC machining of beverage bottle based on Pro/E and master cam," Packaging Engineering, vol. 35, no. 6, pp. 76-78, 2014.

[3] H. Yu, Research on Numerical Simulation of Injection Molding of Thin-Walled Plastic Parts and Optimization of Molding Process Parameters, Zhejiang University of Technology, Hangzhou, China, 2008.

[4] F. Beibei, Numerical Simulation and Process Optimization in Injection Mold Design, Hefei University of Technology, Hefei, China, 2016.

[5] H. Wang, "Optimization of injection molding parameters based on orthogonal test method," Shanghai Plastics, vol. 47, no. 2, pp. 58-62, 2019.

[6] C. Tang, Q. Xia, and B. Zhang, "Hybrid optimization of injection molding process for instrument shell based on response surface model," Plastics Industry, vol. 46, no. 6, pp. 37-40, 2018.

[7] L. Jing, X. Guo, X. Yang et al., "Optimization of injection molding process parameters of automobile air conditioning shell mounting plate based on moldflow and taguchi orthogonal test," Journal of Lanzhou Institute of Technology, vol. 23, no. 3, pp. 76-78, 2016.

[8] B. P. Kumar, P. Venkataramaiah, and J. S. Ganesh, "Optimization of process parameters in injection moulding of a polymer composite product by using gra," Materials Today: Proceedings, vol. 18, no. Pt 7, pp. 4637-4647, 2019.

[9] F. Hentati, H. Ismail, N. Masmoudi, and C. Bradai, "Optimization of the injection molding process for the PC/ABS parts by integrating taguchi approach and CAE simulation," The International Journal of Advanced Manufacturing Technology, vol. 104, no. 9-12, pp. 4353-4363, 2019.

[10] S. M. S. Mukras, H. M. Omar, and F. A. al-Mufadi, "Experimental-based multi-objective optimization of injection molding process parameters," Arabian Journal for Science and Engineering, vol. 44, no. 9, pp. 7653-7665, 2019.

[11] L. Wang, Research on Mold Design and CAE Application of Automobile Thin Wall Injection Parts, Jilin University, Changchun, China, 2010.

[12] X. Guo and G. Ma, "Design of injection mold for charger shell based on UG," Mold Industry, vol. 39, no. 4, pp. 50-52, 2013.
[13] Yi Liu, Research on Improving Weld Line of Products by Hot Runner Sequential Injection Molding, South China University of Technology, Guangzhou, China, 2009.

[14] J. Wang, P. Wang, and F. Zhu, "Application status and research progress of injection mold CAE technology," Inner Mongolia Petrochemical Industry, vol. 15, no. 8, pp. 5-6, 2005.

[15] Y. Zhang and Y. Li, "Analysis of variance of orthogonal design for void grouting material at slab bottom," Low Temperature Building Technology, vol. 35, no. 11, pp. 16-18, 2013.

[16] I. Lizhen, Q. Liang, J. pan et al., "Optimization of molding process parameters of automobile gear lever based on orthogonal test," China Plastics, vol. 33, no. 7, pp. 50-56, 2019.

[17] Y. Shi, W. fan, M. sang et al., "Study on optimization of power spinning parameters of connecting rod bushing based on signal to noise ratio and grey correlation analysis," Foundry Technology, vol. 38, no. 9, pp. 2261-2264, 2017.

[18] W. Meng, Application Research on Process Parameter Optimization of Automobile Top Cover Based on Taguchi Method and Finite Element Analysis, Shenyang University, Shenyang, China, 2017.

[19] H. Wu, X. Qin, L. Yang et al., "Optimization of process parameters of plastic parts based on taguchi method," Intelligent Manufacturing, vol. 23, no. 7, pp. 35-37, 2016.

[20] L. Chen and H. Wang, "Optimization of process parameters of thin-walled asymmetric injection molded parts with one mold and two cavity by taguchi method," Plastics Industry, vol. 40, no. 11, pp. 50-53, 2012. 